Для цитирования: Лубсанова С.В., Петрунько О.В., Гриф В.Л., Сымбелова Т.А., Убеева Е.А. Стресс, тревога и депрессия у медицинских работников, оказывающих помощь пациентам с COVID-19 в Республике Бурятия. Сибирский вестник психиатрии и наркологии. 2021; 3 (112): 48-55. https://doi.org/10.26617/1810-3111-20213(112)-48-55

\title{
Стресс, тревога и депрессия у медицинских работников, оказывающих помощь пациентам с COVID-19 в Республике
}

\section{Бурятия}

\section{Лубсанова С.В.. ${ }^{1,}$, Петрунько О.В. ${ }^{2}$, Гриф В.Л.. ${ }^{3}$ Сымбелова Т.А. Убеева Е.A. ${ }^{1}$}

${ }^{1}$ Бурятский государственный университет им. Доржи Банзарова

Россия, 670000, Улан-Удэ, ул. Смолина, $24 a$

${ }^{2}$ Иркутская государственная медицинская академия последипломного образования филиал ФГБОУ ДПО РМАНПО Минздрава России

Россия, 664049, Иркутск, м-н Юбилейный, 100

${ }^{3}$ Республиканский психоневрологический диспансер

Россия, 67000, Улан-Удэ, ул. Рабочая, $1 \mathrm{~A}$

${ }^{4}$ Республиканская клиническая инфекичионная больница

Россия, 67004, Улан-Удэ, ул. Пирогова, 9 A

\section{PEЗЮME}

Актуальность. При пандемии COVID-19 медицинские работники испытывают профессиональные риски, так как осуществляют трудовую деятельность в условиях повышенной нагрузки с беспрецедентным количеством тяжелобольных пациентов, часто непредсказуемым течением болезни, высокими показателями смертности, необходимостью ношения средств индивидуальной защиты и связанными с этим физиологическим дискомфортом, потребностью повышения квалификации в области диагностики и терапии новой коронавирусной инфекции, стигматизацией и страхом заражения себя и близких, что вызывает проблемы психического здоровья - стрессовые, тревожные и депрессивные расстройства. Цель исследования: оценка проявлений стресса, тревоги и депрессии у медицинских работников, оказывающих помощь пациентам с COVID-19 в Республике Бурятия. Материалы и методы. В анонимном невыборочном опросе приняли участие 108 медицинских работников (48 врачей, 39 медсестер/медбратьев, 21 младший медицинский работник), оказывающих помощь пациентам с COVID-19 в Республике Бурятия. Симптомы стресса и тревоги оценивались по русской версии шкалы Стресс и тревога во время вирусной эпидемии - 9-пунктный опросник (SAVE-9) для медицинского персонала, тревожные и депрессивные проявления - по Госпитальной шкале тревоги и депрессии (HADS). Результаты. По данным шкалы SAVE-9 респонденты часто или постоянно беспокоились, что члены семьи или друзья заразятся от них (30,6\%), что могут заразиться сами $(25,9 \%)$, что у коллег будет больше работы из-за их отсутствия на работе вследствие возможного карантина, что коллеги могут обвинить их из-за повышенной рабочей нагрузки (20,4\%). Среди опрошенных медицинских работников отмечен высокий уровень тревожных $(36,1 \%)$ и депрессивных $(38,9 \%)$ симптомов по шкале HADS. Заключение. Для индивидуализации лечебно-реабилитационных и профилактических мер медицинским работникам, оказывающим помощь пациентам с COVID-19 в Республике Бурятия, необходимо уточнение роли в возникновении стрессовой, тревожной и депрессивной симптоматики таких показателей, как пол, возраст, национальность, должность, наличие перенесенной новой коронавирусной инфекции.

\section{Ключевые слова: COVID-19, депрессия, тревога, стресс, медицинские работники, SAVE-9, HADS.}

\section{ВВЕДЕНИЕ}

Пандемия COVID-19 оказывает существенное влияние на психическое здоровье медицинских работников, непосредственно работающих с пациентами с новой коронавирусной инфекцией. Это обусловлено повышенной профессиональной нагрузкой с рекордной долей тяжелобольных пациентов, часто непредсказуемым течением болез- ни, высокими показателями смертности, необходимостью ношения средств индивидуальной защиты и связанными с этим физиологическими неудобствами, потребностью повышения квалификации в области диагностики и терапии новой коронавирусной инфекции, стигматизацией и страхом заражения себя, членов семьи и близких. 
По данным современных исследований, многие медицинские работники, участвовавшие в лечении и уходе за пациентами с COVID-19, испытывали проблемы с психическим здоровьем, включая депрессию и тревогу, бессонницу и дистресс $[1-12,20]$. Обзор последних работ о распространенности депрессии, тревоги и бессонницы среди 33062 медработников во время эпидемии COVID-19 показал, что значительная часть медработников испытывает нарушения настроения и сна. Так, тревога оценивалась в 12 исследованиях с совокупной распространенностью $23,2 \%$, депрессия - в 10 исследованиях с уровнем распространенности $22,8 \%$, распространенность бессонницы в 5 исследованиях - 38,9\% [1].

Проблемы с психическим здоровьем у работников здравоохранения, оказывающих помощь пациентам с COVID-19, могут не только влиять на возможность выполнения ими своих профессиональных обязанностей, но и иметь долгосрочные негативные последствия. При этом подавляющее большинство из них самостоятельно не обращаются за психологической или психиатрической помощью [7]. В журнале Lancet Psychiatry опубликован призыв к получению объективных данных о последствиях пандемии COVID-19 для психического здоровья всего населения и уязвимых групп, таких как медицинские работники [13]. При этом подчеркивается, что исследования психического здоровья во время кризиса, такого как пандемия COVID-19, являются деликатной темой и должны проводиться с соблюдением этических норм [14]. Современным приоритетом является мониторинг показателей психического здоровья, прежде всего настроения, сна, уровня стресса, с целью разработки стратегии терапии и профилактики психических нарушений у медицинских работников.

\section{ЦЕЛЬ ИССЛЕДОВАНИЯ}

Оценка проявлений стресса, тревоги и депрессии у медицинских работников, оказывающих помощь пациентам с COVID-19 в Республике Бурятия.

\section{МАТЕРИАЛЫ И МЕТОДЫ}

В анонимном невыборочном опросе приняли участие 108 человек: 48 врачей, 39 медсестер и медбратьев, 21 младший медицинский работник. Исследование проводилось в ноябре-декабре 2020 г. в период второй волны новой коронавирусной инфекции COVID-19 в Республике Бурятия с ростом показателей заболеваемости, госпитализаций и смертности. Респонденты принимали непосредственное участие в диагностике и лечении пациентов с COVID-19 на базе двух ЛПУ г. УланУдэ: ГБУЗ «Городская больница № 4» $(\mathrm{n}=68)$, ГБУЗ «Республиканская клиническая инфекционная больница» $(\mathrm{n}=40)$.
В соответствии с целью исследования нами разработан структурированный опросник, включающий следующие разделы: социальнодемографические показатели (пол, возраст, национальность, семейное положение), профессиональный статус (должность, стаж работы), наличие или отсутствие перенесенной новой коронавирусной инфекции. Симптомы стресса и тревоги оценивались по русской версии шкалы Стресс и тревога во время вирусной эпидемии - 9пунктный опросник (SAVE-9) для медицинского персонала (Stress and Anxiety to Viral Epidemics 9 items (SAVE-9) for Healthcare workers) [15], тревожные и депрессивные проявления - по госпитальной шкале тревоги и депрессии (Hospital Anxiety and Depression Scale, HADS).

Среди опрошенных преобладали женщины $(\mathrm{n}=80,74,1 \%)$. Средний возраст респондентов на момент исследования составил $40,9 \pm 1,1$ года, возраст старше 40 лет выявлен более чем у половины респондентов $(\mathrm{n}=60 ; 55,6 \%)$. Стаж работы по специальности более 15 лет отмечен у $38,9 \%(\mathrm{n}=42)$. Анализ семейного положения показал преобладание замужних/женатых $(59,3 \%, \mathrm{n}=64)$ и меньшую встречаемость холостых $(21,3 \%, \mathrm{n}=23)$ и разведенных $(19,4 \%, n=21)$. В обследованной выборке выявлено преобладание представителей коренного населения Республики Бурятия (буряты) $(\mathrm{n}=64$; $59,3 \%)$. К моменту проведения опроса 51 респондент $(47,2 \%)$ уже перенесли новую коронавирусную инфекцию.

Статистическая обработка данных произведена на основе программы Statistica 10.0 for Windows с использованием непараметрического критерия $\chi^{2}$ Пирсона и критерия Стьюдента.

\section{РЕЗУЛЬТАТЫ}

Средний балл по шкале SAVE-9 в изученной выборке медицинских работников составил $11,8 \pm 0,6$. С учетом результатов ранее проведенного исследования [16] о величине порогового балла для SAVE-9, равной 18, предсказывающей с высокой степенью статистической значимости появление тревожной симптоматики, количество опрошенных со средним баллом по шкале SAVE9 больше или равно 18 составило $23,1 \%(\mathrm{n}=25)$.

В соответствии с данными, полученными по шкале SAVE-9, респонденты часто или постоянно беспокоились, что члены семьи или друзья заразятся от них $(\mathrm{n}=33 ; 30,6 \%)$, что могут заразиться сами $(\mathrm{n}=28 ; 25,9 \%)$, что у коллег возрастет профессиональная нагрузка из-за их отсутствия на работе вследствие возможного карантина и они могут обвинить их в возросшем объеме рабочей нагрузки $(\mathrm{n}=22 ; 20,4 \%)$, беспокоились, что вирусная вспышка будет продолжаться бесконечно $(\mathrm{n}=19 ; 17,6 \%)$, опасались, что их здоровье ухудшится в связи с вирусной инфекцией $(\mathrm{n}=19$; 
$17,6 \%)$, более чаще чем обычно обращали внимание на небольшие признаки (симптомы) своего физического самочувствия ( $\mathrm{n}=14 ; 13,0 \%)$, после получения опыта работы в условиях пандемии стали более скептичны к своей работе $(\mathrm{n}=9$; $8,3 \%$ ), беспокоились о возможном избегании общения с ними со стороны окружающих, несмотря на то что риск их заражения был сведен к минимуму (n=6; 5,6\%), после приобретенного опыта работы в условиях COVID-19 считают, что будут избегать лечить больных с вирусными заболеваниями $(\mathrm{n}=5 ; 4,6 \%)$.

Средний показатель тревоги по шкале HADS составил 6,0土0,4 балла. Проявления тревоги по шкале HADS отмечены более чем у трети исследуемых (n=39; 36,1\%): субклинически выраженная тревога (8-10 баллов) - 24,1\% (n=26), клинически выраженная тревога (11 баллов и выше) $12,0 \%$ ( $=13)$. Средний показатель депрессии по шкале HADS составлял 6,4 $\pm 0,4$ балла. Проявления депрессии по шкале HADS выявлены у $38,9 \%$ : субклинически выраженная депрессия (810 баллов $)$ - 20,4\% (n=22), клинически выраженная депрессия (11 баллов и выше) - 18,5\% (n=20).

Результаты сравнительного анализа проявлений стресса, тревоги и депрессии у медицинских работников в зависимости от пола и возраста представлены в таблице 1.

Т а б л и ц а 1. Распределение проявлений стресса, тревоги и депрессии у обследованных медицинских работников в зависимости от пола и возраста

\begin{tabular}{|c|c|c|c|c|c|c|c|c|}
\hline \multirow[t]{2}{*}{ Показатель } & \multicolumn{2}{|c|}{$\begin{array}{c}\text { Женщины } \\
(\mathrm{n}=80)\end{array}$} & \multicolumn{2}{|c|}{$\begin{array}{c}\text { Мужчины } \\
(\mathrm{n}=28)\end{array}$} & \multicolumn{2}{|c|}{$\begin{array}{c}\text { Возраст более } \\
40 \text { лет }(\mathrm{n}=60)\end{array}$} & \multicolumn{2}{|c|}{$\begin{array}{c}\text { Возраст до } 40 \\
\text { лет }(\mathrm{n}=48)\end{array}$} \\
\hline & Абс. & $\%$ & Абс. & $\%$ & Абс. & $\%$ & Абс. & $\%$ \\
\hline Субклинически выраженная тревога по шкале HADS & 18 & 22,5 & 8 & 28,6 & 18 & 30,0 & 8 & 16,7 \\
\hline Клинически выраженная тревога по шкале HADS & 11 & 13,8 & 2 & 7,1 & 10 & 16,7 & 3 & 6,3 \\
\hline Субклинически выраженная депрессия по шкале HADS & 16 & 20,0 & 6 & 21,4 & 13 & 21,7 & 9 & 18,8 \\
\hline Клинически выраженная депрессия по шкале HADS & 17 & 21,3 & 3 & 10,7 & 15 & 25,0 & 5 & 10,4 \\
\hline По шкале SAVE-9 18 и более баллов & 20 & 25,0 & 5 & 17,8 & 17 & 28,3 & 8 & 16,7 \\
\hline Средний балл по шкале SAVE-9 & \multicolumn{2}{|c|}{12,2} & \multicolumn{2}{|c|}{10,8} & \multicolumn{2}{|c|}{$12,8^{*}$} & \multicolumn{2}{|c|}{$10,7 *$} \\
\hline Средний балл по шкале тревоги HADS & \multicolumn{2}{|c|}{6,2} & \multicolumn{2}{|c|}{5,2} & \multicolumn{2}{|c|}{$6,9 *$} & \multicolumn{2}{|c|}{$4,8 *$} \\
\hline Средний балл по шкале депрессии HADS & \multicolumn{2}{|c|}{6,6} & \multicolumn{2}{|c|}{5,8} & \multicolumn{2}{|c|}{$7,1 *$} & \multicolumn{2}{|c|}{$5,5 *$} \\
\hline
\end{tabular}

П р и м е ч а н и е. Статистическая значимость различий: * $-\mathrm{p}<0,05$.

Среди медицинских работников у женщин по сравнению с мужчинами на уровне тенденции зарегистрированы более высокие показатели среднего балла по шкале SAVE-9 (12,2 и 10,8), шкале тревоги HADS $(6,2$ и 5,2) и шкале депрессии HADS $(6,6$ и 5,8), клинически выраженная тревога $(13,8$ и 7,1$)$ и клинически выраженная депрессия $(21,3$ и 10,7) по шкале HADS.

Распределение респондентов по возрастному параметру продемонстрировало более высокую частоту проявлений депрессии и тревоги по шкале HADS в возрастной группе лиц старше 40 лет. Выявлены статистически значимые различия с более высоким показателем среднего балла по шкале SAVE-9 в группе медицинских работников старше 40 лет по сравнению с группой лиц до 40 лет (12,8 и 10,7 соответственно, $\mathrm{p}<0,05)$, более высоким показателем среднего балла по шкале тревоги HADS $(6,9$ и 4,8 соответственно, $\mathrm{p}<0,05)$, а также более высоким показателем среднего балла по шкале депрессии $\operatorname{HADS}(7,1$ и 5,5, $\mathbf{p}<0,05)$.

Сравнительный анализ проявлений стресса, тревоги и депрессии у медицинских работников в зависимости от национальности продемонстрировал в группе коренного населения (буряты) на уровне тенденции более низкие показатели среднего балла по шкале SAVE-9 (11,6 против 12,1), по шкале HADS - клинически выраженную тревогу $(9,4$ против 15,9). Статистически значимые различия выявлены по частоте встречаемости клинически выраженной депрессии по шкале HADS c более низким показателем в группе коренного населения (буряты) Республики Бурятия по сравнению с представителями других национальностей $(10,9 \%$ и 29,5\%, p<0,05) (табл. 2).

При анализе семейного статуса медицинских работников определен статистически значимый более низкий уровень клинически выраженной депрессии по шкале HADS в группе респондентов, состоящих в браке, по сравнению с не состоящими в браке (холост или разведен) $(9,4 \%$ и $31,8 \%$ соответственно, $\mathrm{p}<0,05)$. На уровне тенденции зарегистрированы более низкий показатель субклинически выраженной тревоги по шкале HADS $(20,3$ и 29,5) и более высокий показатель субклинически выраженной депрессии по шкале $\operatorname{HADS}(25,0 \%$ и $13,6 \%)$ (табл. 2).

В зависимости от занимаемой должности среди трех групп респондентов (врачи, медсестры/медбратья, младшие медицинские работники) статистически значимый более высокий показатель выявлен у младших медицинских работников по сравнению с врачами $(7,9$ и $5,9, \mathrm{p}<0,05)$ по шкале депрессии HADS (табл. 3). 
Сравнительный анализ проявлений стресса, тревоги и депрессии у медицинских работников в зависимости от стажа работы показал, что при трудовой деятельности менее 15 лет по сравнению группой работающих свыше 15 лет обнаружен статистически значимый более низкий показатель среднего балла по шкале тревоги HADS $(5,1$ и $7,3, \mathrm{p}<0,05)$. Помимо того, статистически значимо с более редкой частотой регистрировалась клинически выраженная тревога по шкале $\operatorname{HADS}(6,1 \%$ и $21,4 \%, \mathrm{p}<0,05)$ (табл. 4).
Среди медицинских работников, которые к моменту проведения исследования уже перенесли новую коронавирусную инфекцию, по сравнению с не переболевшими на момент исследования COVID-19 респондентами отмечена тенденция к более низким показателям субклинической и клинической тревоги и депрессии по шкале HADS и выявлен статистически значимый более низкий показатель среднего балла по шкале SAVE-9 (10,5 и 13,0, p<0,05 (табл. 4).

Т а $б$ л и ц а 2. Распределение проявлений стресса, тревоги и депрессии у обследованных медицинских работников в зависимости от национальности и семейного положения

\begin{tabular}{|c|c|c|c|c|c|c|c|c|}
\hline \multirow[t]{2}{*}{ Показатель } & \multicolumn{2}{|c|}{$\begin{array}{c}\text { Коренное } \\
\text { население } \\
\text { (буряты) } \\
(\mathrm{n}=64)\end{array}$} & \multicolumn{2}{|c|}{$\begin{array}{c}\text { Другие нацио- } \\
\text { нальности } \\
(\mathrm{n}=44)\end{array}$} & \multicolumn{2}{|c|}{$\begin{array}{c}\text { Состоят в браке } \\
(\mathrm{n}=64)\end{array}$} & \multicolumn{2}{|c|}{$\begin{array}{l}\text { Не состоят в } \\
\text { браке }(\mathrm{n}=44)\end{array}$} \\
\hline & Абс. & $\%$ & Абс. & $\%$ & Абс. & $\%$ & Абс. & $\%$ \\
\hline Субклинически выраженная тревога по шкале HADS & 13 & 20,3 & 13 & 29,5 & 13 & 20,3 & 13 & 29,5 \\
\hline Клинически выраженная тревога по шкале HADS & 6 & 9,4 & 7 & 15,9 & 8 & 12,5 & 5 & 11,4 \\
\hline Субклинически выраженная депрессия по шкале HADS & 13 & 20,3 & 9 & 20,5 & 16 & 25,0 & 6 & 13,6 \\
\hline Клинически выраженная депрессия по шкале HADS & 7 & $10,9 *$ & 13 & $29,5^{*}$ & 6 & $9,4^{*}$ & 14 & $31,8^{*}$ \\
\hline По шкале SAVE-9 18 и более баллов & 13 & 20,3 & 12 & 27,3 & 14 & 21,9 & 11 & 25,0 \\
\hline Средний балл по шкале SAVE-9 & \multicolumn{2}{|c|}{11,6} & \multicolumn{2}{|c|}{12,1} & \multicolumn{2}{|c|}{11,8} & \multicolumn{2}{|c|}{11,9} \\
\hline Средний балл по шкале тревоги HADS & \multicolumn{2}{|c|}{5,7} & \multicolumn{2}{|c|}{6,3} & \multicolumn{2}{|c|}{6,1} & \multicolumn{2}{|c|}{5,8} \\
\hline Средний балл по шкале депрессии HADS & \multicolumn{2}{|c|}{5,9} & \multicolumn{2}{|c|}{7} & \multicolumn{2}{|c|}{6,0} & \multicolumn{2}{|c|}{6,8} \\
\hline
\end{tabular}

П р и м е ч а н и е. Статистическая значимость различий: * $-\mathrm{p}<0,05$.

Т а б л и ц а 3. Распределение проявлений стресса, тревоги и депрессии у обследованных медицинских работников в зависимости от занимаемой должности

\begin{tabular}{|c|c|c|c|c|c|c|}
\hline \multirow[t]{2}{*}{ Показатель } & \multicolumn{2}{|c|}{ Врачи $(\mathrm{n}=48)$} & \multicolumn{2}{|c|}{$\begin{array}{c}\text { Медсестры/ } \\
\text { медбратья }(\mathrm{n}=39)\end{array}$} & \multicolumn{2}{|c|}{$\begin{array}{c}\text { Младшие медицинские } \\
\text { работники }(\mathrm{n}=21)\end{array}$} \\
\hline & Абс. & $\%$ & Абс. & $\%$ & Абс. & $\%$ \\
\hline Субклинически выраженная тревога по шкале HADS & 11 & 22,9 & 9 & 23,1 & 6 & 28,6 \\
\hline Клинически выраженная тревога по шкале HADS & 6 & 12,5 & 6 & 15,4 & 1 & 4,8 \\
\hline Субклинически выраженная депрессия по шкале HADS & 11 & 22,9 & 8 & 20,5 & 3 & 14,3 \\
\hline Клинически выраженная депрессия по шкале HADS & 6 & 12,5 & 6 & 15,4 & 8 & 38,1 \\
\hline По шкале SAVE-9 18 и более баллов & 8 & 16,7 & 10 & 25,6 & 7 & 33,3 \\
\hline Средний балл по шкале SAVE-9 & \multicolumn{2}{|c|}{11,6} & \multicolumn{2}{|c|}{11,4} & \multicolumn{2}{|c|}{13,3} \\
\hline Средний балл по шкале тревоги HADS & \multicolumn{2}{|c|}{5,9} & \multicolumn{2}{|c|}{6,2} & \multicolumn{2}{|c|}{5,6} \\
\hline Средний балл по шкале депрессии HADS & \multicolumn{2}{|c|}{$5,9 *$} & \multicolumn{2}{|c|}{6,0} & \multicolumn{2}{|c|}{$7,9 *$} \\
\hline
\end{tabular}

П р и м е ч а н и е. Статистическая значимость различий: * $-\mathrm{p}<0,05$.

Т а б л и ц а 4. Распределение проявлений стресса, тревоги и депрессии у обследованных медицинских работников в зависимости от стажа работы и перенесенной новой коронавирусной инфекции

\begin{tabular}{|c|c|c|c|c|c|c|c|c|}
\hline \multirow{3}{*}{ Показатель } & \multicolumn{4}{|c|}{ Стаж работы } & \multicolumn{4}{|c|}{ COVID-19 в анамнезе } \\
\hline & \multicolumn{2}{|c|}{$\begin{array}{c}\text { более } 15 \text { лет } \\
(\mathrm{n}=42)\end{array}$} & \multicolumn{2}{|c|}{$\begin{array}{c}\text { менее } 15 \text { лет } \\
(\mathrm{n}=66)\end{array}$} & \multicolumn{2}{|c|}{$\begin{array}{l}\text { болел } \\
(\mathrm{n}=51)\end{array}$} & \multicolumn{2}{|c|}{$\begin{array}{c}\text { не болел } \\
(\mathrm{n}=57)\end{array}$} \\
\hline & Абс. & $\%$ & Абс. & $\%$ & Абс. & $\%$ & Абс. & $\%$ \\
\hline Субклинически выраженная тревога по шкале HADS & 13 & 31,0 & 13 & 19,7 & 11 & 21,6 & 15 & 26,3 \\
\hline Клинически выраженная тревога по шкале HADS & 9 & $21,4 *$ & 4 & $6,1 *$ & 6 & 11,8 & 7 & 12,3 \\
\hline Субклинически выраженная депрессия по шкале HADS & 7 & 16,7 & 15 & 22,7 & 10 & 19,6 & 12 & 21,1 \\
\hline Клинически выраженная депрессия по шкале HADS & 11 & 26,2 & 9 & 13,6 & 6 & 11,8 & 14 & 24,6 \\
\hline По шкале SAVE-9 18 и более баллов & 11 & 26,2 & 14 & 21,2 & 8 & 15,7 & 17 & 29,8 \\
\hline Средний балл по шкале SAVE-9 & \multicolumn{2}{|c|}{12,2} & \multicolumn{2}{|c|}{11,6} & \multicolumn{2}{|c|}{$10,5^{*}$} & \multicolumn{2}{|c|}{$13,0^{*}$} \\
\hline Средний балл по шкале тревоги HADS & \multicolumn{2}{|c|}{$7,3^{*}$} & \multicolumn{2}{|c|}{$5,1^{*}$} & \multicolumn{2}{|c|}{6,0} & \multicolumn{2}{|c|}{5,9} \\
\hline Средний балл по шкале депрессии HADS & \multicolumn{2}{|c|}{7,0} & \multicolumn{2}{|c|}{5,9} & \multicolumn{2}{|c|}{6,2} & \multicolumn{2}{|c|}{6,5} \\
\hline
\end{tabular}


П р и м е ч а н и е. Статистическая значимость различий: * $-\mathrm{p}<0,05$.

\section{ОБСУЖДЕНИЕ}

Проведенное исследование имеет ряд ограничений. Относительно небольшое количество включенных в исследование медицинских работников связано с изучением регионального аспекта - население Республики Бурятия на 2021 г. составляет 985431 чел.; соблюдением этических норм - включение только лиц, давших добровольное согласие на участие. В связи с работой всех участников исследования в «красной зоне» оказания помощи пациентам с COVID-19 клиническая оценка состояния обследуемых врачомпсихиатром не проводилась. Использование опросника и шкал для оценки уровня стресса, тревоги и депрессии не позволяет диагностировать расстройство в соответствии с имеющимися диагностическими критериями, а свидетельствует лишь о наличии симптомов нарушений психической сферы.

Среди медицинских работников, оказывающих помощь пациентам с новой коронавирусной инфекцией в Республике Бурятия, отмечен высокий уровень тревожных $(36,1 \%)$ и депрессивных (38,9\%) симптомов по шкале HADS. Полученные данные согласуются с результатами отечественных и зарубежных исследований [1-12, 20].

Среди медицинских работников, участвовавших в данном исследовании, подавляющее большинство составляли женщины $(74,1 \%)$. Однако исследование не выявило статистически значимых различий по показателям стресса, тревоги и депрессии в зависимости от пола. Гендерных различий не было отмечено и в исследованиях отечественных [12] и зарубежных коллег [8]. Ряд авторов указывает на зависимость частоты проявлений тревоги и депрессии от пола с преобладанием у женщин - медиков, работающих с пациентами с COVID-19 [5, 6, 9].

Результаты собственного исследования продемонстрировали более высокие показатели стресса, тревоги и депрессии среди медицинских работников в возрасте старше 40 лет, что противоречит ранее опубликованным отечественным и зарубежным работам, где указывалось, что в возрасте до 40 лет регистрировались более высокие показатели тревоги и депрессии среди медицинских работников $[6,9,12]$.

При оценке стресса и тревоги во время вирусной эпидемии по шкале SAVE-9 около трети $(30,6 \%)$ опрошенных «часто» или «постоянно» беспокоились, что члены семьи, коллеги или друзья заразятся от них, 25,9\% испытывали беспокойство в связи с угрозой, что сами могут заразиться опасной инфекцией. Преобладание среди медицинских работников опасений заражения своих близких и себя отмечают и авторы других исследований $[6,12]$.

Сравнительный статистический анализ проявлений стресса, тревоги и депрессии у медицинских работников в зависимости от национальности продемонстрировал в группе коренного населения (буряты) более низкие показатели клинически выраженной депрессии по сравнению с другими национальностями. На этнокультуральные особенности психических расстройств у бурят указывалось ранее [17], в связи с чем требуется дальнейшее изучение данного аспекта с учетом национальных и религиозных особенностей населения Республики Бурятия.

В нашем исследовании при анализе медицинских работников по семейному статусу был определен более низкий уровень клинически выраженной депрессии в группе состоящих в браке по сравнению с теми, кто не состоял в браке, был холост или разведен. Однако китайскими исследователями выявлено, что при пандемии COVID19 медики, состоящие в браке, имели более высокие показатели психической травматизации по сравнению с холостыми медработниками [10].

Статистически значимые различия при оценке стресса, тревоги и депрессии в зависимости от занимаемой должности (врачи, медсестры/медбратья, младшие медицинские работники) были определены лишь по более высокому показателю среднего балла по шкале депрессии HADS среди младших медицинских работников по сравнению с врачами. Преобладание нарушений психической сферы среди младшего медицинского персонала по сравнению с врачами представлено в обзорной статье коллективом соавторов из Индии [5].

Нами получены данные о том, что при стаже трудовой деятельности менее 15 лет в сравнении со стажем работы свыше 15 лет у медицинских работников отмечались статистически значимые более низкие показатели среднего балла по шкале тревоги HADS и более редкая частота встречаемости тревожной симптоматики. Эти данные противоречат материалам исследования китайских психиатров, где на большой выборке ( $\mathrm{n}=1838)$ продемонстрирована связь между меньшим опытом работы и повышенным риском посттравматического стресса у медицинских работников [4].

Полученные данные определяют высокую потребность медицинского персонала в социальной (создание условий трудовой деятельности, в которых возможно достижение максимальной эффективности и результативности) и психологической поддержке. В условиях планетарного системного COVID-кризиса необходимо расширять предпринимаемые многоуровневые и индивидуа- 
лизированные меры, которые позволят повысить устойчивость и снизить уязвимость данного контингента.

\section{ЗАКЛЮЧЕНИЕ}

Проведенное исследование показало высокую распространенность стресса, тревоги и депрессии у медицинских работников, задействованных в оказании помощи пациентам с COVID-19 в Pecпублике Бурятия, что требует разработки, совершенствования и реализации профилактических, терапевтических и реабилитационных психологопсихотерапевтических мероприятий для данной категории лиц. На сегодняшний день подготовлены и используются рекомендации по вопросам организации психологической и психотерапевтической помощи работникам системы здравоохранения в связи с распространением новой коронавирусной инфекции COVID-19 [18, 19]. С учетом специфики работы и высокой степени ответственности медицинского персонала, оказывающего помощь пациентам с COVID-19 в условиях «красной зоны», приоритетным направлением для данной уязвимой категории лиц является организация дистанционной психологической поддержки и в случае необходимости психотерапевтической и психиатрической помощи $[11,18]$.

Индивидуализация и повышение качества лечебно-реабилитационных и профилактических мер медицинским работникам, оказывающим помощь пациентам с COVID-19 в Республике Бурятия, возможны с учетом роли в возникновении стрессовой, тревожной и депрессивной симптоматики таких показателей, как пол, возраст, национальность, должность медицинского работника, наличие перенесенной новой коронавирусной инфекции.

\section{КОНФЛИКТ ИНТЕРЕСОВ}

Авторы заявляют об отсутствии конфликта интересов в связи с публикацией данной статьи.

\section{ИСТОЧНИК ФИНАНСИРОВАНИЯ}

Авторы заявляют об отсутствии спонсорских или иных финансовых источников при проведении настоящего исследования.

\section{СООТВЕТСТВИЕ ПРИНЦИПАМ ЭТИКИ}

Исследование соответствует этическим стандартам Хельсинкской Декларации ВМА и одобрено этическим комитетом ФГБОУ ВО «Бурятский государственный университет им. Доржи Банзарова» (протокол № 3 от 2203.2021 г.). От участников исследования получено добровольное информированное согласие.

\section{ЛИТЕРАТУРА/REFERENCES}

1. Pappa S, Ntella V, Giannakas T, Giannakoulis VG, Papoutsi E, Katsaounou P. Prevalence of depression, anxiety, and insomnia among healthcare workers during the COVID-19 pandemic: A systematic review and meta-analysis. Brain Behav Immun. 2020 Aug;88:901-907. doi: 10.1016/j.bbi.2020.05.026. Epub 2020 May 8. Erratum in: Brain Behav Immun. 2021 Feb;92:247. PMID: 32437915; PMCID: PMC7206431.

2. Das N. Psychiatrist in post-COVID-19 era - Are we prepared? Asian J Psychiatr. 2020 Jun;51:102082. doi: 10.1016/j.ajp.2020.102082. Epub 2020 Apr 7. PMID: 32283513; PMCID: PMC7139240.

3. Liu S, Yang L, Zhang C, Xiang YT, Liu Z, Hu S, Zhang B. Online mental health services in China during the COVID-19 outbreak. Lancet Psychiatry. 2020 Apr;7(4):e17-e18. doi: 10.1016/S22150366(20)30077-8. Epub 2020 Feb 19. PMID: 32085841 ; PMCID: PMC7129099.

4. Lai J, Ma S, Wang Y, Cai Z, Hu J, Wei N, Wu J, Du H, Chen T, Li R, Tan H, Kang L, Yao L, Huang M, Wang H, Wang G, Liu Z, Hu S. Factors Associated With Mental Health Outcomes Among Health Care Workers Exposed to Coronavirus Disease 2019. JAMA Netw Open. 2020 Mar 2;3(3):e203976. doi: 10.1001/jamanetworkopen.2020.3976. PMID: 32202646; PMCID: PMC7090843.

5. Spoorthy MS, Pratapa SK, Mahant S. Mental health problems faced by healthcare workers due to the COVID-19 pandemic-A review. Asian J Psychiatr. 2020 Jun;51:102119. doi: 10.1016/j.ajp.2020.102119. Epub 2020 Apr 22. PMID: 32339895; PMCID: PMC7175897.

6. Mosolova E., Sosin D., Mosolov S. Stress and anxiety in healthcare workers during COVID-19 pandemic. In book: Origin and Impact of COVID-19 Pandemic Originating From SARS-CoV-2 Infection Across the Globe [Working Title]. June 2021 DOI:10.5772/intechopen.98292

7. Xiang YT, Yang Y, Li W, Zhang L, Zhang Q, Cheung $\mathrm{T}, \mathrm{Ng} \mathrm{CH}$. Timely mental health care for the 2019 novel coronavirus outbreak is urgently needed. Lancet Psychiatry. 2020 Mar;7(3):228-229. doi: 10.1016/S2215-0366(20)30046-8. Epub 2020 Feb 4. PMID: 32032543; PMCID: PMC7128153.

8. Chen Y, Zhou H, Zhou Y, Zhou F. Prevalence of self-reported depression and anxiety among pediatric medical staff members during the COVID-19 outbreak in Guiyang, China. Psychiatry Res. 2020 Jun;288:113005.

doi: 10.1016/j.psychres.2020.113005. Epub 2020 Apr 16. PMID: 32315886; PMCID: PMC7160637.

9. Rossi R, Socci V, Pacitti F, Di Lorenzo G, Di Marco A, Siracusano A, Rossi A. Mental Health Outcomes Among Frontline and Second-Line Health Care Workers During the Coronavirus Disease 2019 (COVID-19) Pandemic in Italy. JAMA Netw Open. 2020 May 1;3(5):e2010185. doi: 10.1001/jamanetworkopen.2020.10185. PMID: 32463467; PMCID: PMC7256664.

10. Li X, Yu H, Yang W, Mo Q, Yang Z, Wen S, Zhao F, Zhao W, Tang Y, Ma L, Zeng R, Zou X, Lin H. Depression and Anxiety Among Quarantined People, Community Workers, Medical Staff, and General Population in the Early Stage of COVID-19 Epidemic. Front Psychol. 2021 Mar 26;12:638985. 
doi: 10.3389/fpsyg.2021.638985. PMID: 33841273; PMCID: PMC8033150.

11. Мосолов С.Н. Проблемы психического здоровья в условиях пандемии COVID-19. Журнал неврологии и психиатрии им. С.С. Корсакова. 2020. T. 120, № 5. C. 7-15. Mosolov SN. Problem of mental health in the situation of COVID-19 pandemic. S.S. Korsakov Journal of Neurology and Psychiatry. 2020;120(5):7-15. (in Russian). https://doi.org/10.17116/jnevro20201200517

12. Бачило Е.В., Барыльник Ю.Б., Шульдяков А.А. Ефремов А.А., Новиков Д.Е. Психическое здоровье медицинских работников в период пандемии COVID-19 в России: результаты перекрестного интернет-опроса. Психиатрия и психофармакотерапия. 2020. Т. 22, № 3. С. 49-55. Bachilo EV, Barylnik YuB, Shuldyakov AA, Efremov AA, Novikov DE. Mental health medical workers during the COVID-19 pandemic in Russia: a crosssectional study. Psychiatry and Psychopharmacotherapy. 2020;3:49-55 (in Russian).

13. Holmes EA, O'Connor RC, Perry VH, Tracey I, Wessely S, Arseneault L, Ballard C, Christensen H, Cohen Silver R, Everall I, Ford T, John A, Kabir T, King K, Madan I, Michie S, Przybylski AK, Shafran R, Sweeney A, Worthman CM, Yardley L, Cowan K, Cope C, Hotopf M, Bullmore E. Multidisciplinary research priorities for the COVID-19 pandemic: a call for action for mental health science. Lancet Psychiatry. 2020 Jun;7(6):547-560. doi: 10.1016/S2215-0366(20)30168-1. Epub 2020 Apr 15. PMID: 32304649; PMCID: PMC7159850.

14. Townsend E, Nielsen E, Allister R, Cassidy SA. Key ethical questions for research during the COVID-19 pandemic. Lancet Psychiatry. 2020 May;7(5):381-383. doi: 10.1016/S22150366(20)30150-4. PMID: 32353264; PMCID: PMC7185919.

15. Mosolov S., Chung Seockhoon, Shin Y.-W., Suh A. SAVE-9 (Russian): Stress and Anxiety to Viral Epidemics - 9 items for Healthcare workers / Стресс и тревога во время вирусной эпидемии - 9пунктный опросник (SAVE-9) для медицинского персонала. Projects: Stress and anxiety in healthcare workers during COVID-19 pandemic UUCM SAVE-9. 2020 May. doi: 10.13140/RG.2.2.16943.56480/3
16. Mosolova E, Chung S, Sosin D, Mosolov S. P.663 Stress and anxiety among healthcare workers during the coronavirus disease 2019 pandemic in Russia. Eur Neuropsychopharmacol. 2020 Nov;40:S375. doi: 10.1016/j.euroneuro.2020.09.486. Epub 2020 Nov 17. PMCID: PMC7670894.

17. Балаганова Т.Б. Этнокультуральные особенности психических расстройств у бурят : автореф. дис. ... к.м.н. Новосибирск, 2006. 19 с. Balaganova TB. Ethnocultural features of mental disorders in Buryats: PhD thesis Novosibirsk, 2006:19 (in Russian).

18. Булыгина В.Г. Психологическая помощь медикам, работающим с пациентами с наличием COVID-19. Информационное письмо. М., 2020. 14 c. Bulygina VG. Psychological assistance to physicians working with patients with COVID-19. Newsletter. Moscow, 2020:14 (in Russian).

19. Треушникова Н.В., Бачило Е.В., Бородин В.И., Антонова А.А. Рекомендации для медицинских работников, находящихся в условиях повышенных психоэмоциональных нагрузок в период пандемии COVID-19. М., 2020. 46 c. Treushnikova NV, Bachilo EV, Borodin VI, Antonova AA. Recommendations for healthcare workers in conditions of increased psycho-emotional stress during the COVID-19 pandemic]. Moscow, 2020:46 (in Russian).

20. Стоянова И.Я., Иванова А.А., Смирнова Н.С., Лебедева В.Ф., Руденко Л.С., Магденко О.В., Бохан Н.А. Психические нарушения, развивающиеся в кризисно-экстремальной ситуации пандемии коронавируса: актуальная проблематика и особенности психолого-психотерапевтического консультирования. Stoyanova IYa, Ivanova AA, Smirnova NS, Lebedeva VF, Rudenko LS, Magdenko OV, Bokhan NA. Mental disorders developing in the crisisextremal situation of the coronavirus pandemic: focal problems and features of psychologicalpsychotherapeutic counseling. Siberian Herald of Psychiatry and Addiction Psychiatry. 2021; 1 (110): 7177. (in Russian) https://doi.org/10.26617/1810-31112021-1(110)-71-77

Поступила в редакцию 17.08.2021 Утверждена к печати 6.09.2021

Лубсанова Светлана Викторовна, к.м.н., доцент, доцент Медицинского института ФГБОУ ВО «Бурятский государственный университет им. Доржи Банзарова». Author iD 656023. SPIN-код 9294-3313.

Петрунько Ольга Вячеславна, к.м.н., доцент, заведующий кафедрой психиатрии и наркологии ИГМАПО филиал ФГБОУ ДПО РМАНПО Минздрава России. Author iD 407791. SPIN-код 2041-5505. petrounko@ mail.ru

Гриф Виталий Леонтьевич, главный врач ГБУЗ «Республиканский психоневрологический диспансер». mail@rpnd-rb.ru

Сымбелова Татьяна Аюшеевна, главный врач ГБУЗ «Республиканская клиническая инфекционная больница». gib_70@mail.ru

Убеева Елена Александровна, к.м.н., старший преподаватель Медицинского института ФГБОУ ВО «Бурятский государственный университет им. Доржи Банзарова». ubeeva.ip@ mail.ru 
Лубсанова Светлана Викторовна, lsv1972@mail.ru

UDC 612.017.2:616.891.6:616.8-008.64:656.071.6:616-036.2(571.54)

For citation: Lubsanova S.V., Petrunko O.V., Grif V.L., Symbelova T.A., Ubeeva E.A. Stress, anxiety and depression in healthcare workers caring for COVID-19 patients in the Republic of Buryatia. Siberian Herald of Psychiatry and Addiction Psychiatry. 2021; 3 (112): 48-55. https://doi.org/10.26617/1810-3111-2021-3(112)-48-55

\title{
Stress, anxiety and depression in healthcare workers caring for COVID-19 patients in the Republic of Buryatia
}

\section{Lubsanova S.V. ${ }^{1,3}$, Petrunko O.V. ${ }^{2}$, Grif V.L. ${ }^{3}$, Symbelova T.A. ${ }^{4}$, Ubeeva E.A. ${ }^{1}$}

\author{
${ }^{1}$ Dorji Banzarov Buryat State University \\ Smolin Street 24a, 670000, Ulan-Ude, Russian Federation \\ ${ }^{2}$ Irkutsk State Medical Academy of Postgraduate Education - Branch of the Federal State Budgetary \\ Educational Institution of Further Professional Education "Russian Medical Academy of Continuing \\ Professional Education" of the Ministry of Healthcare of the Russian Federation \\ Yubileiny Micro-district 100, 664049, Irkutsk, Russian Federation \\ ${ }^{3}$ Republican Psychoneurological Dispensary \\ Rabochaya Street 1A, 67000, Ulan-Ude, Russian Federation \\ ${ }^{4}$ Republican Clinical Infectious Hospital \\ Pirogova Street, 9 A, 67004, Ulan-Ude, Russian Federation
}

\begin{abstract}
Relevance. In the COVID-19 pandemic, healthcare workers face professional risks, as they work under increased workload with an unprecedented number of critically ill patients, an often unpredictable course of the disease, high mortality rates, the need to wear personal protective equipment and the associated physiological discomfort, the need for advanced training in the diagnosis and treatment of a new coronavirus infection, stigmatization and fear of infecting oneself and loved ones, which causes mental health problems - stress, anxiety and depressive disorders. Objective of the study: to assess the manifestations of stress, anxiety and depression in medical workers providing care to patients with COVID-19 in the Republic of Buryatia. Materials and Methods. 108 medical workers (48 doctors, 39 nurses, 21 junior medical workers) took part in an anonymous non-selective survey, providing care to patients with COVID-19 in the Republic of Buryatia. Symptoms of stress and anxiety were assessed according to the Russian version of the Stress and Anxiety during a viral epidemic scale - a 9-item questionnaire (SAVE-9) for medical personnel, anxiety and depressive manifestations - according to the Hospital Anxiety and Depression Scale (HADS). Results. According to the SAVE-9 scale, respondents often or constantly worried that family members or friends would get infected from them $(30.6 \%)$, that they could get infected themselves $(25.9 \%)$, that colleagues will have more work because of their absence from work due to possible quarantine, which colleagues can blame for the increased workload (20.4\%). Among the surveyed medical workers, there was a high level of anxiety (36.1\%) and depressive (38.9\%) symptoms according to the HADS scale. Conclusion. For the individualization of treatment, rehabilitation and preventive measures, medical workers who provide assistance to patients with COVID-19 in the Republic of Buryatia, it is necessary to clarify the role in the occurrence of stressful, anxiety and depressive symptoms of indicators such as gender, age, nationality, the presence of a postponed new coronavirus infection.
\end{abstract}

\section{Keywords: COVID-19, depression, anxiety, stress, healthcare professionals, SAVE-9, HADS.}

Received August 17.2021

Accepted September 06.2021

Lubsanova Svetlana V., PhD, Assistant Professor, Medical Institute, Dorji Banzarov Buryat State University, Ulan-Ude, Russian Federation; Republican Psychoneurological Dispensary, Ulan-Ude, Russian Federation. Author iD 656023. SPIN-code 9294-3313.

Petrunko Olga V., PhD, Associate Professor, Head of Psychiatry and Narcology Department, Irkutsk State Medical Academy of Postgraduate Education - Branch of the FSBEI FPE RMACPE MOH Russia, Irkutsk, Russian Federation. Author iD 407791. SPIN-code 2041-5505. petrounko@mail.ru

Grif Vitaly L. - Chief Physician, Republican Psychoneurological Dispensary, Ulan-Ude, Russian Federation. mail@rpnd-rb.ru Symbelova Tatyana A. Chief Physician, Republican Clinical Infectious Hospital, Ulan-Ude, Russian Federation. gib_70@mail.ru Ubeeva Elena A., PhD, Senior Lecturer, Medical Institute, Dorji Banzarov Buryat State University, Ulan-Ude, Russian Federation. ubeeva.ip@mail.ru

Lubsanova Svetlana V., 1sv1972@mail.ru 